\title{
NUMERICAL AND EXPERIMENTAL STUDIES ON SHIP MOTIONS INDUCED BY PASSING SHIP
}

\author{
Francisco G. Pedro \\ LNEC - National Laboratory for Civil Engineering, \\ Lisbon, Portugal, fpedro@Inec.pt
}

\author{
João A. Santos \\ ISEL - IPL, Instituto Superior de Engenharia de \\ Lisboa, Instituto Politécnico de Lisboa \\ CENTEC - Centre for Marine Technology and \\ Ocean Engineering, University of Lisbon \\ Portugal, jasantos@dec.isel.ipl.pt
}

\author{
Liliana V. Pinheiro \\ LNEC - National Laboratory \\ for Civil Engineering, Lisbon, \\ Portugal, Ipinheiro@Inec.pt
}

\author{
Conceição J. Fortes \\ LNEC - National Laboratory \\ for Civil Engineering, Lisbon, \\ Portugal, jfortes@Inec.pt
}

\author{
Miguel Hinostroza \\ CENTEC - Centre for Marine \\ Technology and Ocean Engineering, \\ University of Lisbon, Portugal, \\ hinostroza@centec.tecnico.ulisboa.pt
}

\begin{abstract}
To investigate the ability of numerical models to simulate the behavior of moored ships subjected by ship-wake waves, use is made of scale model tests where a ship model sails with constant speed along a straight path at a constant distance from an otherwise motionless ship.

The tests were carried out at one of the wave tanks of the Portuguese Civil Engineering Laboratory (LNEC). The moving ship is a self-propelled scale model of the "Aurora" chemical ship whereas the otherwise motionless ship is a scale model of the "Esso Osaka" tanker. The free-surface elevation was measured with a set of resistive wave gauges and ADVs. The tanker's movements, induced by the wake waves, were measured along the six degrees of freedom with a gyroscope deployed inside the ship.

The numerical model WAMIT provides, in the frequency domain, the quantities required to estimate the hydrodynamic forces associated to the interaction of a free-floating ship with waves. The BAS model uses those hydrodynamic forces to study in the time domain the ship interaction with any sea-waves acting on it. Wind and current actions can also be accounted for.

The results of these numerical models are compared to the measurements made in the several repeats of one of those scalemodel tests, in terms of the response amplitude to several wave components. These comparisons enabled the evaluation and
\end{abstract}

validation of the numerical models parameters' calibration process.

\section{INTRODUCTION}

Waves can hamper cargo operations and compromise the safety of moored ships. In fact, it is not uncommon for waves inside harbors to be responsible for mooring lines' breakage, resulting in costly damages to terminal's structures and ship's hulls. Such waves can be a result of extreme sea states, trapped long waves or even wake waves caused by maneuvering ships.

In the first work to characterize the wave field generated by ships sailing along a straight line, Froude [1] identifies the existence of two wave systems: the transverse waves and the divergent waves. Equal phase lines of these two systems meet along two straight lines that are symmetrical with relation to the ship trajectory. The highest free-surface elevation values do occur along those lines, as well as near the ship's bow.

The theoretical wave pattern generated by a point source that moves with a constant speed obtained by Lord Kelvin [2] is similar to the ship-wake wave pattern. In that work, it is shown that the maximum of the free-surface elevation occurs along two straight lines symmetrical with relation to the point source trajectory making an angle of $38^{\circ} 56^{\prime}$ with each other $\left(19^{\circ} 28^{\prime}\right.$ with the point source trajectory).

Numerical models can characterize the response of ships to waves but still depend on some parameters calibration. In that sense, physical model experiments can be of paramount 
importance as they can replicate, in a controlled environment, wave-ship interactions. It possible, in a laboratory set-up to simulate wake waves with no other disturbances. Otherwise, in a prototype harbor site, wind waves, wind and currents are always inducing ships' movements.

This paper aims at investigating the ability of the numerical models included in numerical package for moored ship behavior, SWAMS [3], to simulate the behavior of such ships subjected to ship-wake waves. For this use is made of scale model tests were a ship model sails with constant speed along a straight path at a constant distance from an otherwise motionless ship.

The scale-model tests were carried out at one of the wave tanks of the Portuguese Civil Engineering Laboratory (LNEC). The moving ship is a self-propelled scale model of the "Aurora" chemical ship whereas the otherwise motionless ship is a scale model of the "Esso Osaka" tanker. Details of the measurements are presented at [4].

After this introduction, the main features of the numerical package SWAMS as well as of its components are described. Then the tests made with the moving "Aurora" scale model and the otherwise motionless "Esso Osaka" scale model are presented. The results from those tests are used in the following chapter to assess the capabilities of the numerical models, first with the time domain and then in the frequency domain.

\section{MOORED SHIP INTERACTION WITH INCIDENT WAVES}

\section{Time-domain approach}

Assuming that the moored ship does not depart much from its equilibrium position it is possible to consider as linear the interaction between the incident wave and the free-floating ship. Then such interaction can be decomposed into two simpler problems, the so-called diffraction problem, where the ship is held motionless subjected to incident waves and the so-called radiation problem where the ship moves in otherwise calm waters in such a way that the forces then acting on the ship match the other forces on the ship (inertia, diffraction, and mooring system forces).

The motion equations along each generalized coordinate $k$ can then be written as

$$
\begin{gathered}
\sum_{j=1}^{6}\left[\left(M_{k j}+m_{k j}\right) \ddot{X}_{j}+\int_{-\infty}^{t} K_{k j}(t-\tau) \dot{X}_{j}(\tau) d \tau+\right. \\
\left.+C_{k j} X_{j}\right]=F_{k}^{D}+F_{k}^{\text {ext }}
\end{gathered}
$$

where $M$ and $C$ are respectively the mass and the hydrostatic restitution matrices of the ship, which depend only on the mass distribution in the ship and on the hull shape. $m$ and $K$ are respectively the added mass and the retardation function matrices. They are associated to the radiation problem, $m_{k j}$ being the force along the generalized coordinate $k$ due to unit acceleration of the ship along coordinate $j\left(\ddot{X}_{j}=1\right)$ and $K_{k j}(\tau)$ a being the time series of the force along $k$ due to an impulsive velocity along $j$ at time $t=0\left(\dot{X}_{i}(t)=\delta(0)\right) . F_{k}^{D}$ is the time series of the diffraction force along the $k$ coordinate whereas $F_{k}^{e x t}$ represents the time series of the remaining external forces along the same coordinate.

The SWAMS numerical package, [3], is the result of coupling numerical models for sea-wave propagation with numerical models for moored ship behavior, thus enabling the identification of dangerous sea states and a better planning of port activities.

To simulate the behavior of moored ships it uses the BAS numerical model [5] which assembles and solves equation Erro! A origem da referência não foi encontrada. considering several sources for the external forces on the moored ship. It includes the constitutive relations for the mooring system elements (mooring lines and fenders) and the wind and current forces, as well as non-linear drift forces and damping not considered in the linear numerical models used to characterize the ship interaction with incident waves. The results of this numerical model are the time-series of the motions along each of the generalized coordinates and of the efforts in the mooring system elements. The key data for this model is the time series of the external forces. Should one have this time series for the ship-wake waves then it would be possible to get the motions of the moored (or of the free-floating) ship subjected to these waves.

\section{Frequency-domain approach}

For a free-floating ship subjected to monochromatic waves of frequency $\omega$, such that the free-surface elevation at one point can be given by $\eta(t)=\zeta_{0} \cos (\theta t)$, the diffraction forces can be written as $F_{k}^{D}(t)=\zeta_{0} F_{k}^{D}(\omega) \cos \left(\omega t+\varphi_{k}\right)$ and the motion of the ship along each generalized coordinate $j$ will be also sinusoidal with frequency $\omega, X_{j}=\zeta_{j} \cos \left(\omega t+\alpha_{j}\right)$. Then, the motion equations become

$$
\begin{gathered}
\sum_{j=1}^{6}\left\{-\omega^{2}\left(M_{k j}-\frac{1}{\omega} \int_{0}^{\infty} K_{k j}(\tau) \sin \omega \tau d \tau\right) \zeta_{j} \cos \left(\omega t+\alpha_{j}\right)+\right. \\
+\zeta_{j} \omega \sin \left(\omega t+\alpha_{j}\right) \int_{0}^{\infty} K_{k j}(\tau) \cos \omega \tau d \tau+ \\
\left.+C_{k j} \zeta_{j} \cos \left(\omega t+\alpha_{j}\right)\right\}=\zeta_{0} F_{k}^{D}(\omega) \cos \left(\omega t+\varphi_{k}(\omega)\right)
\end{gathered}
$$

and one may define the components of the radiation force in phase with the motion acceleration, the so-called added-mass coefficients

$$
a_{k j}(\omega)=m_{k j}-\frac{1}{\omega} \int_{0}^{\infty} K_{k j}(\tau) \sin \omega \tau d \tau
$$


as well as the component in phase with the motion velocity, the so-called damping coefficients

$$
b_{k j}(\omega)=\frac{1}{\omega} \int_{0}^{\infty} K_{k j}(\tau) \cos \omega \tau d \tau
$$

This means that one can use the results from numerical models for ship-wave interaction in the frequency domain to get the added mass matrix, $m$, and the matrix of retardation functions, $K$.

The WAMIT model [6] is one of such models. It uses a panel method (i.e. the wetted hull surface is discretized with rectangular or triangular panels) to solve the integral equations for the strength of the dipoles distributed on each of those panels in the radiation and diffraction problems in the frequency domain. These are irrotational flows of ideal fluids, i.e. no viscosity is considered. From the solutions of those problems it is possible to compute the added mass and damping coefficients $\left(a_{k j}(\omega)\right.$ and $b_{k j}(\omega)$ as well as the amplitude and phase shift of the diffraction forces $\left(F_{k}^{D}(\omega)\right.$ and $\left.\varphi_{k}(\omega)\right)$ for incident waves of unit amplitude $\left(\zeta_{0}=1\right)$. It must be pointed out that the diffraction forces are strongly dependent on the wave incidence angle. The number of frequencies considered does condition the quality of the estimates of the added mass and of the retardation functions matrices. The number of panels per wave length influences the solution of the radiation and diffraction problems in the frequency domain.

\section{SCALE MODEL TESTS}

\section{Equipment and Measuring Techniques}

The main objective of the tests was to characterize the wave field generated by the movement of the "Aurora" ship as well as the motions induced by such wave field on another ship ("Esso Osaka") that would be otherwise motionless near the "Aurora" trajectory and for different advance velocities of this ship.

The tests were carried out in wave tank 6, Figure 1, of the Maritime Hydraulics Testing Hall of the Port and Maritime Structures division of LNEC. This wave tank has a length of 23 $\mathrm{m}$ and a width of $22 \mathrm{~m}$.

In addition to the two ships ("Aurora" and "Esso Osaka"), the tests' equipment included 7 resistive wave probes, 2 acoustic velocimeters (ADV), one gyroscope, one laser scan and one action camera.

The "Esso Osaka" ship was deployed at $\mathrm{x}=11.10 \mathrm{~m}$, with its longitudinal axis perpendicular to the largest side of the tank. The 7 resistive wave probes and the 2 acoustic velocimeters were deployed as shown in Figure 1. The "Aurora" ship made voyages along the smallest side of the tank with different velocities at an intended distance to the "Esso Osaka" of $0.57 \mathrm{~m}$.

The 7 resistive wave gauges measured the free-surface elevation with a sampling rate of $25 \mathrm{~Hz}$. The wave gauges were deployed as shown in Figure 1 and they are meant to characterize the ship-wake wave field generated by the movement of the "Aurora".

To measure the flow velocity associated to that wave field, two acoustic doppler velocimeters were used. They can measure the velocity components along each of the three axes (x, y and $\mathrm{z}$ ) $6 \mathrm{~cm}$ below the undisturbed free surface level, with a sampling rate of $25 \mathrm{~Hz}$. These velocimeters were deployed as shown in Figure 1, close to the wave gauges, Figure 2.

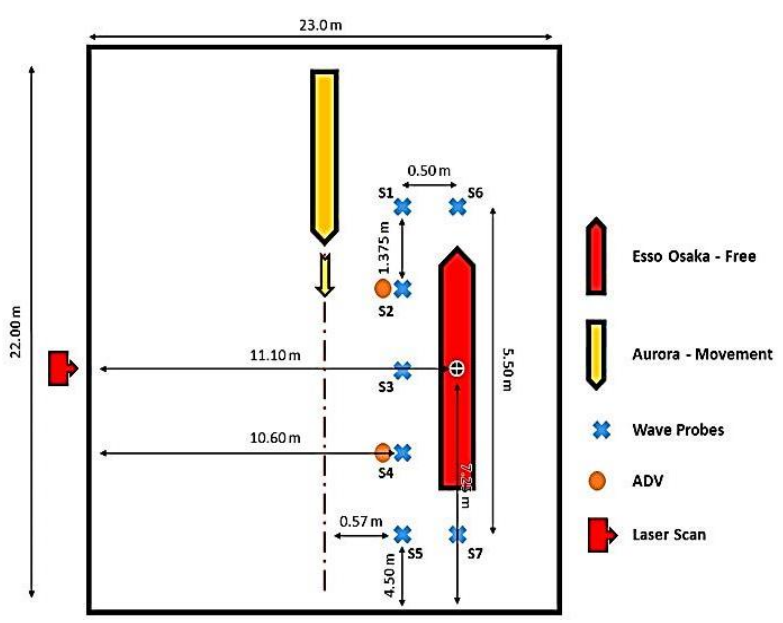

FIGURE 1. Physical model and equipment set-up.
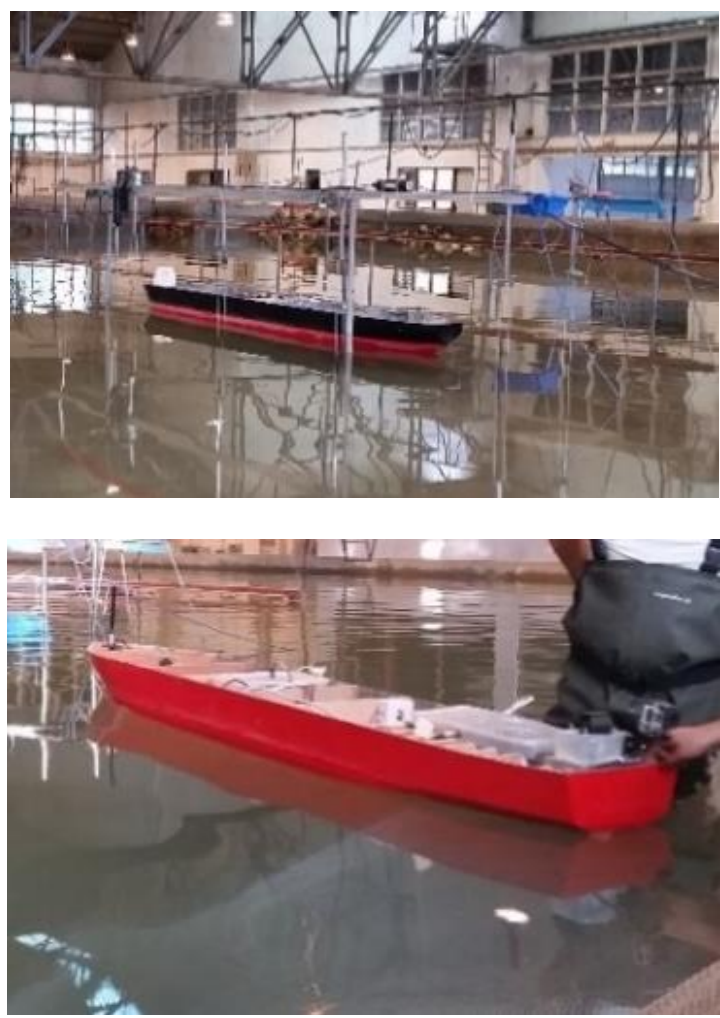

FIGURE 2. Top) "Esso Osaka" ship and resistive wave gauges and velocimeters; Bottom) "Aurora" ship. 
The fiber-optic gyroscope installed at "Esso Osaka" can measure the ship's heading as well as the ship's accelerations along the surge, sway, heave, roll, pitch and yaw movements. From these accelerations, the velocities along the same movements can be estimated. This equipment was deployed in the ship at a position as close as possible to the center of gravity of the ship, namely in what concerns the longitudinal and transversal axes. To manage the synchronization of the acquisition and storage of the gyroscope data, a set of LABVIEW routines was created [7]. The gyroscope data acquisition rate is adaptive, but a post-processing method enabled a $25 \mathrm{~Hz}$ data collection.

The laser scan was deployed outside the wave tank and its beam was perpendicular to the "Esso Osaka" side. The ultimate goal was not only to measure the distance between the "Esso Osaka" and the "Aurora" trajectory, but also to estimate the velocity of the "Aurora" when passing in front of the "Esso Osaka". The action camera was placed also outside the wave tank to film all the tests.

\section{Test conditions}

The "Esso Osaka" ship is a scale model at 1:100 of the hull of the homonym tanker. Its total length is $3.45 \mathrm{~m}$, its beam is $0.54 \mathrm{~m}$ and its maximum draft is $0.23 \mathrm{~m}$.

The "Aurora" ship is a scale model at 1:65.7 of the hull of the homonym chemical tanker. Its total length is $2.59 \mathrm{~m}$, its beam is $0.43 \mathrm{~m}$ and its maximum draft is $0.11 \mathrm{~m}$.

It must be pointed out that the goal of these experiments was not the simulation of the behavior of existing ships - hence the models used are not the reproduction at the same scale of real ships - but rather to characterize the ship wake wave field and the movements it induces in an otherwise motionless ship. Likewise, the mass distribution in the ship models does not aim to reproduce the inertia of real ships but rather the ship drafts leading to the selected Froude numbers and water depth / draft values.

The mass of the hull of the empty "Esso Osaka" (the hull alone) measured at a digital scale was $56.06 \mathrm{Kg}$. The mass of the gyroscope installed at the "Esso Osaka", to measure the ship's linear and angular accelerations, is $5.44 \mathrm{Kg}$. To simulate an intermediate loading condition, 8 cubic concrete blocks, with a total mass of $152.65 \mathrm{Kg}$, were deployed inside the ship's hull. Then the total mass of the ship model (ship hull + concrete blocks + equipment) was $214.15 \mathrm{Kg}$.

The "Aurora" is a self-propelled model. This means that it has an engine, a rudder and a gyroscope that enable its navigation along a selected heading with a given advance speed. The propulsion of the "Aurora" is provided by a DC electric engine whose power is $22 \mathrm{~W}$ and enables a maximum speed of $2.0 \mathrm{~ms}^{-1}$ when the ships sails over a deep-water region with a draft of $0.11 \mathrm{~m}$, [8]. For the tested loading condition of the "Aurora" the mass of the ensemble ship + equipment + loading was $83.78 \mathrm{~kg}$, which corresponds to a draft of $0.105 \mathrm{~m}$ and a displacement of $83.78 \times 10^{-3} \mathrm{~m}^{3}$.
All tests were carried out for an engine power equal to $90 \%$ of the maximum power. For the two water depths tested such engine power led to advance speeds of the "Aurora" close to 0.80 $\mathrm{ms}^{-1}$.

The "Aurora" journeys started with the ship at rest heading perpendicularly to the largest side of the tank (i.e. parallel to the alignment of the free-surface elevation gauges) and ended $4 \mathrm{~m}$ away from wave gauge 5 . Having in mind the angle of the ship trajectory with the lines of maximum height for the ship generated waves (19 $29^{\circ}$, meaning Fs below 0.7), it is not difficult to conclude that, to get meaningful measurements of ship generated waves in all wave gauges, the maximum distance between the ship and the wave-gauges alignment should not exceed $1.60 \mathrm{~m}$.

All journeys started with the "Aurora" $0.57 \mathrm{~m}$ away from the S1 to S5 wave gauges alignment. The tests to be analyzed here are the 10 repeats of a test where the "Aurora" sailed with a speed of $0.8 \mathrm{~ms}^{-1}$ over a water depth of $0.82 \mathrm{~m}$, which corresponds to a deep-water situation for both ships since it is larger than 4.2 times the draft of both ships. This means that the flow around the hull is not influenced by the proximity of the bottom.

Each test consisted of the following steps: a) Adjust the water level in the tank; b) Placing of blocks, weights and equipment on each ship; c) Connection and/or placement of equipment for measuring free surface elevation and flow velocity; d) Calibration of resistive probes; e) Voyage of the "Aurora" ship along the linear path with a pre-set engine power.

\section{RESULTS AND DISCUSSION}

\section{Time-domain}

Before carrying out the time domain simulations of the motions of the free-floating ship subjected to ship-wake waves, it was necessary to correctly define its mass matrix.

Two different sets of parameters had to be calibrated: the ship's mass distribution (in terms of inertias) and the viscous damping factors. For this, use was made of prior decay tests for these oscillations. Such tests were carried out in still water conditions and consisted on imposing an initial roll or pitch angle and measuring the time series of the resulting motions. From the natural period of the resulting oscillation and its decay it is possible to determine if the initial inertia values (or radii of gyration) are correct or if they need to be adjusted. The damping of the oscillation shows that an additional viscous damping has to be added to the motion equations of the ship.

As can be seen in the black continuous line of Figure 3, with the time series of the roll decay test, these are damped oscillations with an almost constant period. This period is controlled by the roll inertia of the ship, whereas a damping coefficient controls the decay rate. 


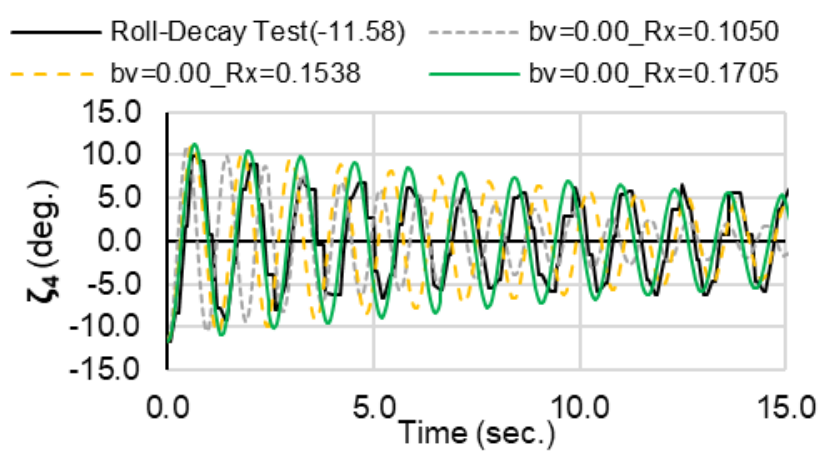

FIGURE 3. Time series of the "Esso Osaka" ship roll decay test. initial roll angle of 9.61 degrees. calibration of the roll inertia and viscous damping.

Due to the port-starboard symmetry common in ships the mass matrix is a diagonal matrix. The grey dashed line in Figure 3 is the time series obtained assuming the ship's mass evenly distributed by the submerged volume of the ship (i.e. gyration radius $r_{44}=0.1050 \mathrm{~m}$ ). As expected, the resulting roll motion from BAS model does not agree with the measured roll motion in the decay test. To get a good match of the roll period oscillation, the gyration radius had to be increased to about $r_{44}=$ $0.1705 \mathrm{~m}$ (i.e. an inertia value of $6.897 \times 10^{-3} \mathrm{~kg} \cdot \mathrm{m}^{2}$ around the $\mathrm{X}$-axis).

It is worth pointing out that the wave generation by the roll motion is responsible for the decay observed in time series of the roll motion of Figure 3. Actually, the figure shows that the predicted roll decay fits quite well the measured one, hence there is no need to add a viscous roll damping factor $\left(b_{4 v i s c}\right)$,

$$
F_{4}^{v i s c}=-b_{4 v i s c} \dot{X}_{4}
$$

considered in the BAS model to account for the viscous torque associated to the roll motion.

Using the same approach for the pitch decay test, one concludes that a gyration radius, $r_{55}=0.7947 m$ (i.e. an inertia value of $149.829 \times 10^{-3} \mathrm{~kg} \cdot \mathrm{m}^{2}$ around the Y-axis) provides a good fit between measured and numerical pitch decay natural period (see Figure 4). Again, there is no need to add a viscous pitch damping factor $\left(b_{5 v i s c}\right)$,

$$
F_{5}^{v i s c}=-b_{5 v i s c} \dot{X}_{5}\left|\dot{X}_{5}\right|
$$

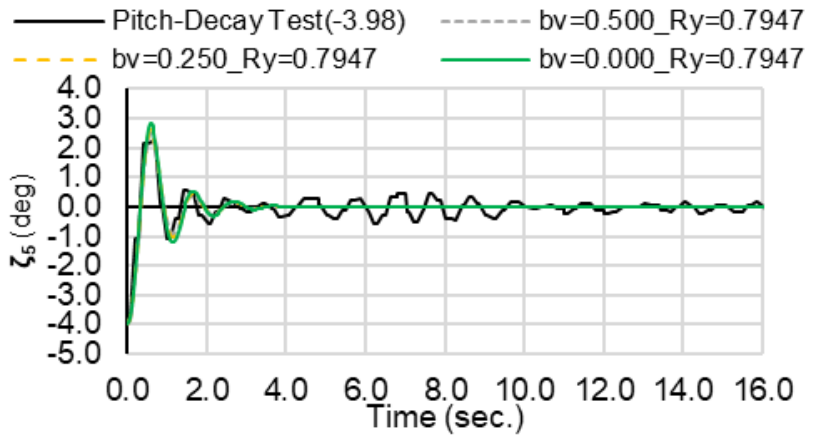

FIGURE 4. Time series of the "Esso Osaka" ship pitch decay test. initial pitch angle of 3.98 degrees. calibration of the pitch inertia and viscous damping.

Once the pitch and roll inertias and viscous damping factors were calibrated, the BAS model was ready to be used to simulate the response of the "Esso Osaka" ship to the ship-wake waves generated by the motion of the "Aurora" ship. For this, the measured waves were fed to the system of equation of motion, considering an incidence angle of around $70^{\circ}$ (angle between the wave crests and the longitudinal axis of the "Esso Osaka" ship of around $20^{\circ}$ ). The free-surface elevation measured in test T07 at wave gauge S1, Figure 5, was used to derive the time series of the diffraction forces on the free-floating "Esso Osaka".

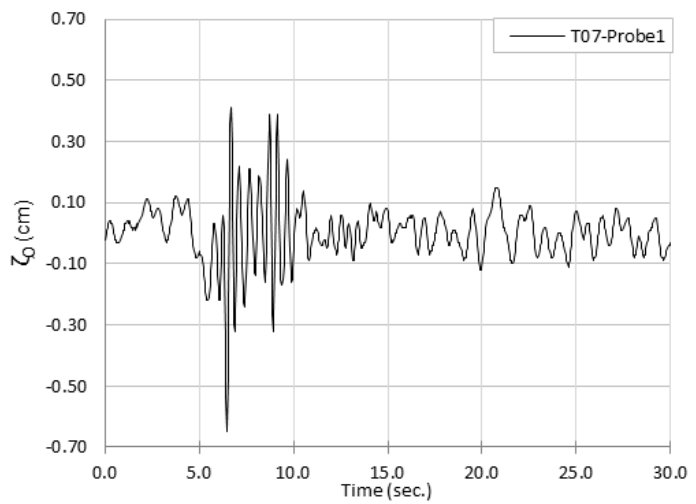

FIGURE 5. Time series of the free-surface elevation measured at wave gauge $\mathrm{S} 1$ in test 07.

However, the BAS model is not meant to model the behavior of free-floating ships. The lack of restitution forces in the horizontal plan, which would be provided by the mooring system elements, implies that the ship does not oscillate around its initial position and a shift from the rest position can be seen in the surge, sway, and yaw motions. Since these motions may interact with the motions in the vertical plan, where restitution forces associated to hydrostatics occur, it is common to get a similar shift in these motions, as can be seen in Figure 6 with the roll motion of the "Esso Osaka" subjected to long-crested waves with the free-surface elevation measured in test 7 . 


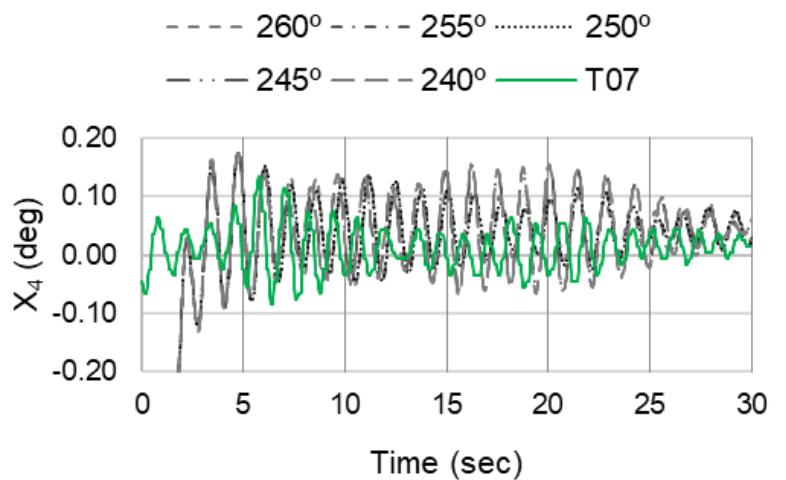

FIGURE 6. Time series of the roll motion of the "Esso Osaka" subjected to the waves of Test 07 .

The same figure shows that the period of the oscillations in the time series of the roll motion predicted by the BAS model is quite similar to the period of the measured "Esso Osaka" roll motion. As to the amplitude, the numerical model results are higher than the measured values. Since there were some doubts on the exact angle of the incident waves on the "Esso Osaka", in addition to the $70^{\circ}$ incidence $\left(250^{\circ}\right.$ in Figure 6$)$ it was decided to test incidence angles between $60^{\circ}$ and $80^{\circ}$ (respectively $240^{\circ}$ and $260^{\circ}$ in Figure 6). However, no significant changes can be observed in the roll motions.

This difference between predicted and measured values becomes worst for the pitch motions, as can be seen in Figure 7. In fact, the predicted pitch motion has an amplitude that is almost zero, whereas the measured pitch amplitude is slightly lower than the measured roll amplitude.

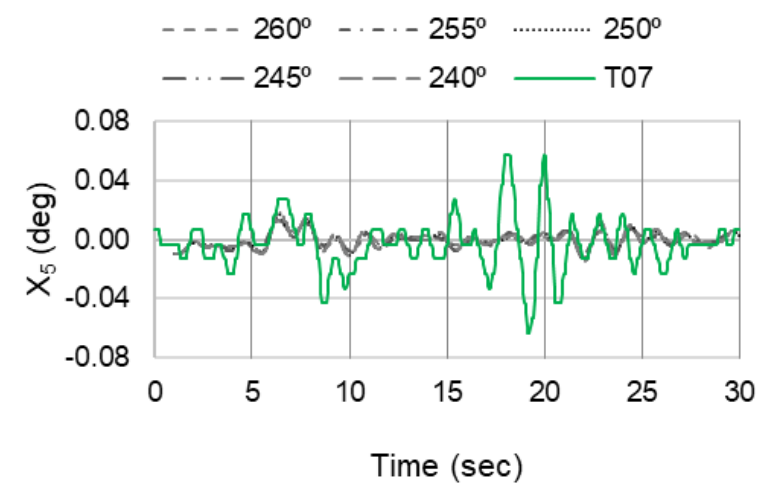

FIGURE 7. Time series of the pitch motion of the "Esso Osaka" subjected to the waves of Test 07 .

\section{Frequency-domain}

The frequency domain results, namely the added mass and damping coefficients from the radiation problem and the diffraction forces, were obtained with a discretization of the wetted hull surface with 6748 panels. The decision of using such a number of panels was based on the convergence of the WAMIT computations. As the number of panels is increased a better convergence is obtained for all the frequencies simulated in the radiation and diffraction problems.

Response amplitude operators (RAOs) are a relation between the amplitude of the free-floating ship oscillation and the amplitude of the incident wave:

$$
R A O_{k}(\omega)=\frac{\zeta_{k}(\omega)}{\zeta_{0}(\omega)}
$$

In Figure 8, the RAOs for the roll motion of the "Esso Osaka" ship are presented for different hull discretizations, ranging from 1000 panels to 6748 panels.

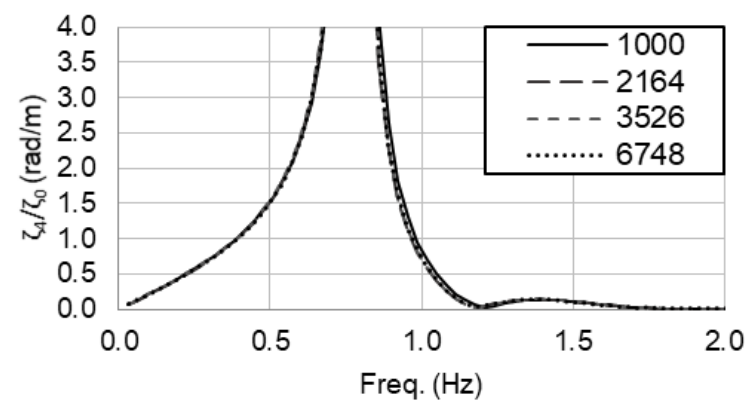

FIGURE 8. Response amplitude operators for the roll motion of the "Esso Osaka" ship for incident waves whose crest makes an angle of $20^{\circ}$ with the longitudinal axis of that ship. Number of panels influence on the WAMIT results.

It is worth point out that such results were obtained with the WAMIT numerical model and so no roll viscous damping was considered although the mass matrix is the fine-tuned one from the decay tests measurements. It is the absence of viscous damping that implies such a high value of the RAO for the $0.75 \mathrm{~Hz}$ frequency.

To compute the RAOs from the measurements, a discrete Fourier transform was applied both on the measured free-surface elevation at wave gauge $\mathrm{S} 1$ and on the measured ship motions. Figure 9, Figure 10, and Figure 11 present the amplitude of the discrete Fourier transforms of, respectively, the free-surface elevation at the wave gauge S1, the roll and the pitch motion of the "Esso Osaka" subjected to ship-wake waves. The figures were divided according to the frequency, e.g. $0 \mathrm{~Hz}$ to $0.5 \mathrm{~Hz}$ and $1.5 \mathrm{~Hz}$ to $5 \mathrm{~Hz}$. into Several repetitions (T01 to T10) of the same experiment are presented in the graphics. 

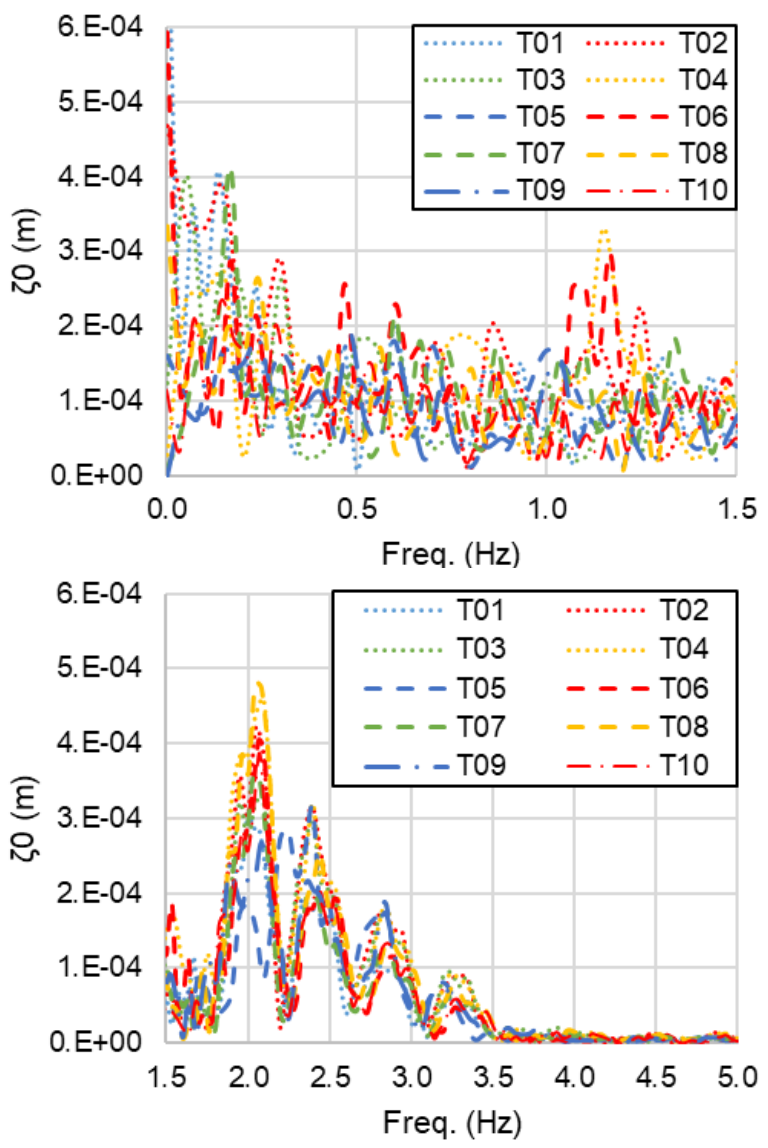

FIGURE 9. Free-surface elevation at wave gauge $s 1$ amplitude spectrum - Top) $0 \mathrm{~Hz}$ to $1.5 \mathrm{~Hz}$; Bottom) $1.5 \mathrm{~Hz}$ to $5.0 \mathrm{~Hz}$.

Figure 12 and Figure 13 present a comparison of RAOs obtained for the 10 largest values of the discrete Fourier transform taken form the experimental measurements (dots and symbols) with the RAOs obtained numerically for five different angles of attack (lines and dotted lines). As in the time domain approach, uncertainties in the incidence angle of the ship-wave waves on the "Esso Osaka" led to consider a range of incidence angles from $240^{\circ}$ to $260^{\circ}$ (angle between the wave crests and the "Esso Osaka" longitudinal axis from $10^{\circ}$ to $30^{\circ}$ ).

Note that $\zeta_{4}$ is the roll motion response amplitude and $\zeta_{0}$ is the incident wave amplitude measured at wave gauge S1.

Probably due to the absence of viscous damping effects or because several frequencies are being looked at individually, the WAMIT RAO values do significantly change for some frequencies, being more important for the pitch RAO than for the roll RAO.
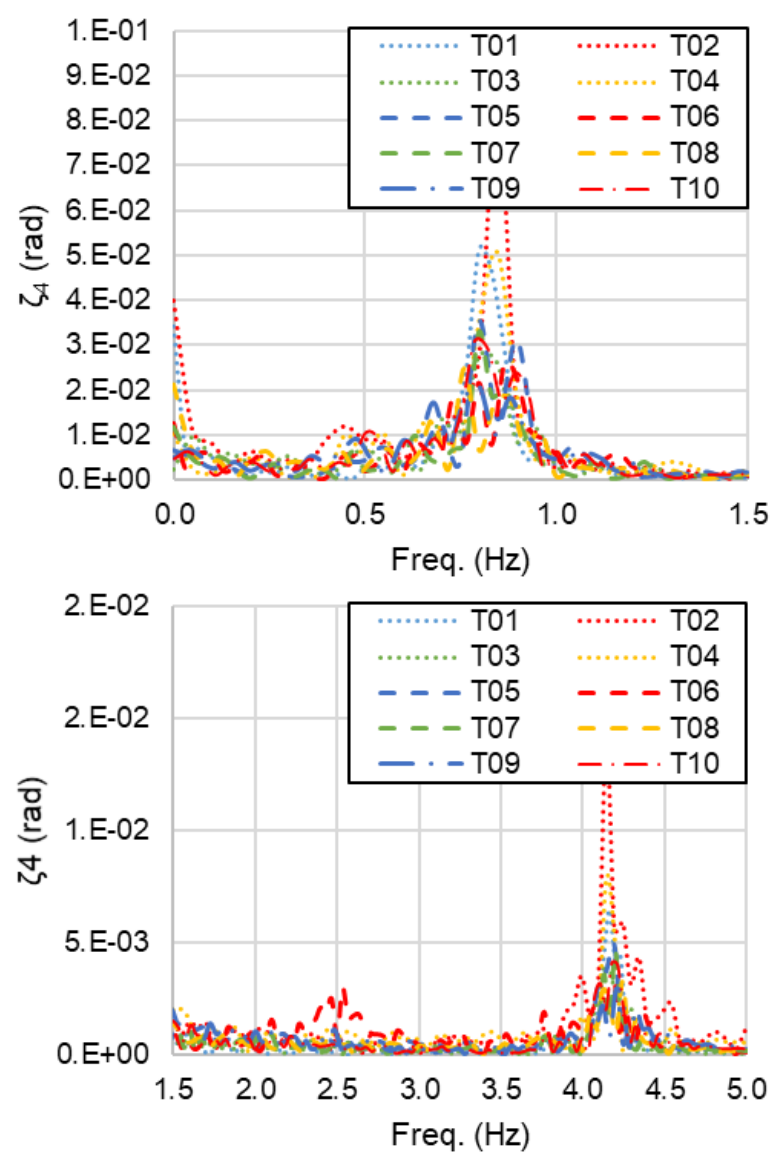

FIGURE 10. "Esso Osaka" roll motion amplitude spectrum Top) $0 \mathrm{~Hz}$ to $1.5 \mathrm{~Hz}$; Bottom) $1.5 \mathrm{~Hz}$ to $5.0 \mathrm{~Hz}$.

There is some degree of accordance between experimental and numerical results. The angle of attack being very hard to control in the experimental repetitions, may be the culprit for the dispersion of values, especially in the pitch RAOs, Figure 13. The RAOs magnitude is well captured as can be seen in Figure 12 and Figure 13, but the key result in those figures is the absence of a single trend line for both the roll and pitch RAOs estimated from the measurements of those movements and from the shipwake wave incident on the "Esso Osaka". This may hint on the difficulty of assuming a long-crested wave acting on the ship, should the linearity of the wave interaction with the free-floating ship be a reasonable approach. Although such absence can be due to changes in the repeats in what concerns the wave direction, which would imply changes from one RAO line to another, one should also bear in mind that the ship-wake wave field is composed by the superposition of two waves with different directions (a divergent and a transversal one).

Despite the simplifying assumptions of the WAMIT model, it may be concluded that the magnitude of the RAOs functions is well estimated with this model. 

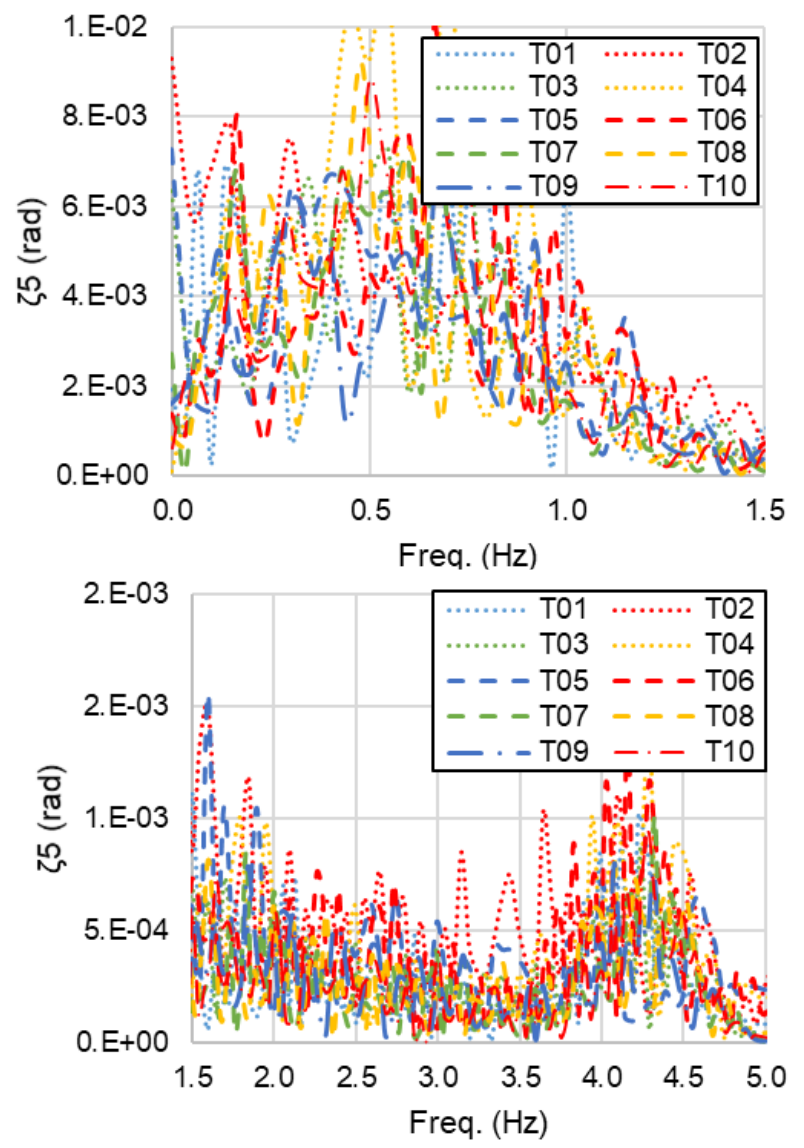

FIGURE 11. "Esso Osaka" pitch motion amplitude spectrum Top) $0 \mathrm{~Hz}$ to $1.5 \mathrm{~Hz}$; Bottom) $1.5 \mathrm{~Hz}$ to $5.0 \mathrm{~Hz}$.

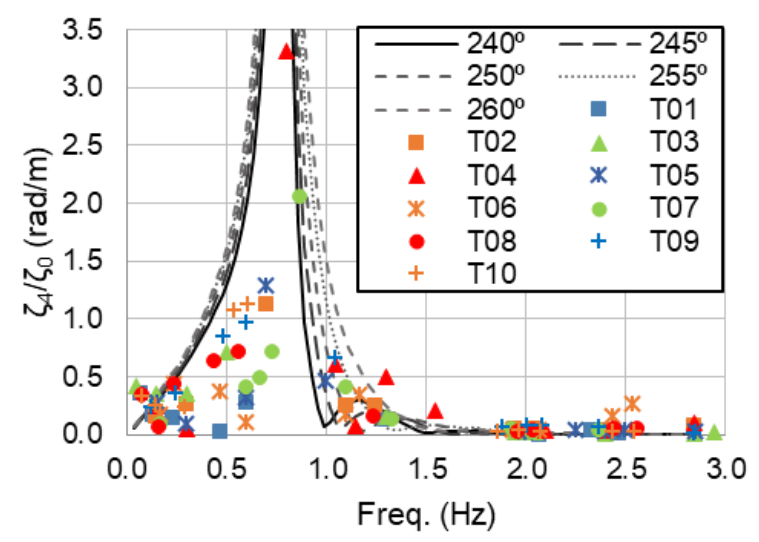

FIGURE 12. RAOs for the "Esso Osaka" roll motion.

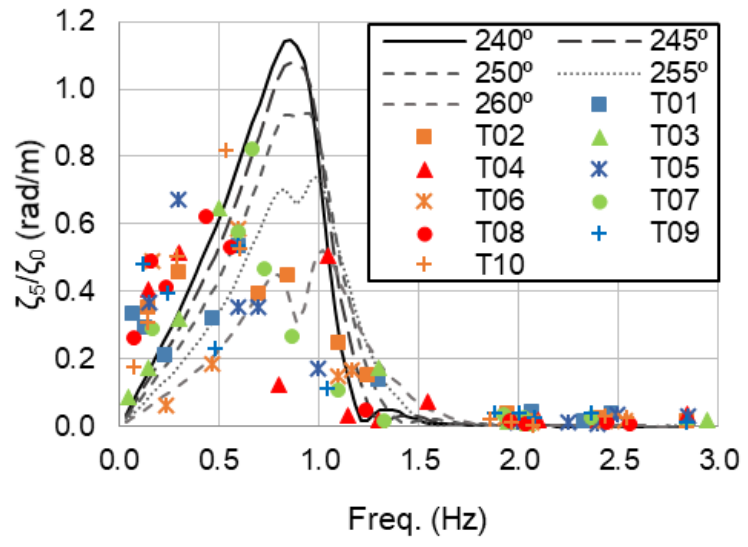

FIGURE 13. Response amplitude operators for the "Esso Osaka" pitch motion.

\section{CONCLUSIONS}

Measurements made at scale model tests were used to investigate the ability of numerically modelling the behavior of an otherwise motionless ship model (the "Esso Osaka" ship) subjected to ship-wake waves generated by another ship model (the "Aurora" ship) that sails nearby.

The time series obtained in the decay tests enabled one to calibrate the mass distribution of the motionless ship as well as of the viscous damping forces in the roll and pitch motions that are not considered in the numerical model WAMIT, which is used to provide the values to define the hydrodynamic forces in the wave-ship interaction.

In the time-domain simulation of the ship interaction with the ship-wake waves (carried out with the BAS model), those waves were assumed as long-crested ones making a $20^{\circ}$ angle (approximately) with the "Esso Osaka" longitudinal axis.

The response amplitude operators (RAOs) for the pitch and roll motions obtained from the discrete Fourier transform of time series measured in the scale model tests were compared to the RAOs obtained with the WAMIT numerical model directly in the frequency domain. Intrinsic in this numerical simulation is the assumption of the incident waves being long-crested ones.

Both in the time and in the frequency domain numerical simulations, a $20^{\circ}$ range, centered at the expected incidence angle of the ship-wake waves, was considered for the direction of the long-crested waves that simulate those waves.

The time series for the roll motion showed that the absence of a restitution force on the horizontal plan for the free-floating ship makes it difficult to get time series that oscillate around the ship's rest position. Although the periods of the roll oscillations are reasonably predicted by the numerical model BAS, the amplitude of those oscillations was smaller than the one observed in the scale model tests. This can be due to the poor representation of the diffraction forces, in this case the forces associated to the ship-wake waves. 
The RAOs for the roll and pitch motions computed with the numerical model WAMIT do have the magnitude of the RAOs obtained from the discrete Fourier transform of the time series measured in the scale-model tests. It is worth pointing out that it was not possible to identify a clear trend in RAOs points obtained from the scale model tests. This can be due to the changes in the incidence angle between test repetitions or to the fact that ship-wake waves are poorly represented as the superposition of sinusoidal waves.

The next step in this work will be an improved representation of the time series of the forces on the motionless ship along each of the six generalized coordinates due to shipwake waves. Although the common use of the BAS numerical model assumes the stationarity of the sea state acting on the ship, this numerical model copes with any time series for the waves acting on the ship.

\section{ACKNOWLEDGMENTS}

This work is a contribution to the M\&MSHIPS project "Maneuvering \& Moored SHIPS in ports" (PTDC/EMSTRA/5628/2014) funded by the Foundation for Science and Technology.

\section{REFERENCES}

[1] Froude, W. 1877. "Experiments upon the effect produced on the wave-making resistance of ships by length of parallel middle body". Trans. Inst. of Naval Architects, vol.18, pp.77-87.

[2] Lord Kelvin (Sir William Thomson), 1887. "On ship waves". Proc. Inst. of Mech. Engineers, pp. 409-433.

[3] Pinheiro, L. V.; Fortes, C. J.E.M.; Santos, J. A.; Fernandes, J. L.M. Numerical Simulation of The Behaviour of a Moored Ship Inside an Open Coast Harbour V International Conference on Computational Methods in Marine Engineering MARINE 2013. B. Brinkmann and P. Wriggers (Eds)

[4] Pedro, F., Santos,e J.A.,Hinostroza, M., Pinheiro, L., Fortes, C.J.E.M. (2017) Experimental Characterization of Ship Motions Induced by Passing Ships. International Short Course and Conference on Applied Coastal Research (SCACR2017), IH Cantabria, Santander, Spain.

[5] Mynett, A.E., Keunig, P.J. e Vis, F.C., 1985. The dynamic behaviour of moored ships inside a harbour configuration. Int. Conf. on Numerical Modelling of Ports and Harbours, Birmingham, England: 23-25 April 1985. Cranfield: BHRA, The Fluid Engineering Centre.

[6] Korsemeyer F.T., Lee C.-H., Newman J.N., Sclavounos P.D., 1988. The analysis of wave effects on tension-leg platforms, 7th International Conference on Offshore Mechanics and Arctic Eng., Houston, Texas, pp. 1-14.
[7] Hinostroza, M.A., Guedes Soares, C. 2016. "Parametric estimation of the directional wave spectrum from ship motions". Int..J. Mar. Eng, 158, pp. A-121-A-130.

[8] Perera, L. P., Ferrari, V., Santos, F. P., Hinostroza, M. A. and Soares, C. G. 2015. "Experimental evaluations on ship autonomous navigation and collision avoidance by intelligent guidance". IEEE Journal of Oceanic Engineering, 40(2), 374-38 